\title{
Autologous Anti-CD19 CAR-CD28 T-cells ET019002
}

National Cancer Institute

\section{Source}

National Cancer Institute. Autologous Anti-CD19 CAR-CD28 T-cells ET019002. NCI

Thesaurus. Code C162856.

A preparation of autologous T-lymphocytes that have been transduced with a lentiviral vector to express a chimeric antigen receptor (CAR) consisting of a sing le chain variable fragment (scFv) of anti-CD19, coupled to the costimulatory domain of CD28, with potential immunostimulating and antineoplastic activities. Upon transfusion, the autolog ous anti-CD19 CAR-CD28 T-cells ET 019002 target, bind to, and induce selective toxicity in CD19-expressing B-cells. The CD19 antigen is a B-cell-specific cell surface antigen expressed in all B-cell lineage malignancies. 